FVC were considered, the 5-year extrapolated survival was increased to $86.3 \%$ (Figure 2).

Conclusion: Long-term experience of nintedanib treatment in SSc-ILD patients is lacking so far, therefore we modeled and extrapolated the 52-week treatment efficacy of nintedanib on the long-term FVC course and survival in SSc-ILD patients from the EUSTAR database. We could demonstrate a significant reduction of FVC decline by extrapolating the annual treatment effects of nintedanib from the SENSCIS trial from 1 to 5 years in EUSTAR. Translating these reductions of FVC decline into survival, the 5-year mortality rate was reduced from $18 \%$ to $13 \%$
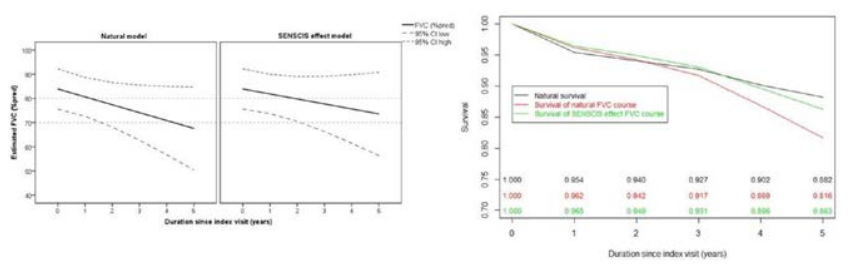

Disclosure of Interests: Anna-Maria Hoffmann-Vold Speakers bureau: Boehringer Ingelheim, Actelion, Roche, Merck Sharp \& Dohme, Lilly, Consultant of: Actelion, Boehringer Ingelheim, Roche, Bayer, Merck Sharp \& Dohme, ARXX, Lilly and Medscape, Grant/research support from: Boehringer Ingelheim, Dörte Huscher: None declared, Paolo Airò Speakers bureau: Boehringer Ingelheim, Consultant of: Bristol-Myers-Squibb, Novartis, Elisabetta Zanatta Speakers bureau: Boehringer Ingelheim, Actelion, GSK, Paid instructor for: GSK, Consultant of: Boehringer Ingelheim, GSK, Patricia Carreira Speakers bureau: Actelion, Boehringer Ingellheim, Janssen, GSK, Paid instructor for: Boehringer Ingelheim, Consultant of: AbbVie, Boehringer Ingelheim, VivaCell, Emerald Health Pharmaceuticals, Gesynta Pharma, Sanofi Genzyme, Grant/research support from: Roche, GSK, Yannick Allanore Consultant of: Honorarium received from Boehringer, Medsenic

Sanofi, Menarini, Grant/research support from: Grants received from Alpine, Ose Immunogenetics, Ulf Müller-Ladner Speakers bureau: Boehringer Ingelheim, Consultant of: Boehringer Ingelheim, Alessandro Giollo: None declared, Maria Rosa Pozzi: None declared, CAROLINA SOUZA MULLER Speakers bureau: Boehinger Ingelheim, Janssen, Roche, LIBBS, Bristol-Myers-Squib, Radim Bečvář Consultant of: Actelion, Boehringer Ingelheim, Michele ludici: None declared, Dominik Majewski Speakers bureau: Boehringer Ingelheim - 2 x paid as a speaker, Armando Gabrielli Grant/research support from: Pfizer, CSL Behring, Margarida Alves Employee of: Boehringer Ingelheim, Nils Schoof Employee of: Boehringer Ingelheim International $\mathrm{GmbH}$, Oliver Distler Speakers bureau: Boehringer Ingelheim, Medscape, IQone, Roche, Consultant of: Abbvie, Acceleron Pharma, Amgen, AnaMar, Arxx Therapeutics, Baecon Discovery, Blade Therapeutics, Bayer, Boehringer Ingelheim, ChemomAb, Corbus Pharmaceuticals, CSL Behring, Galapagos NV, Glenmark Pharmaceuticals, GSK, Horizon (Curzion) Pharmaceuticals, Inventiva, iQvia, Italfarmaco, Kymera Therapeutics, Lilly, Medac, Mitsubishi Tanabe Pharma, MSD, Novartis, Pfizer, Roche, Sanofi, Serodapharm, Topadur, Target Bioscience and UCB, Grant/research support from: Kymera Therapeutics, Mitsubishi Tanabe

DOI: 10.1136/annrheumdis-2021-eular.2522

\section{POS0317 THE PERFORMANCE OF DIFFUSING CAPACITY FOR MONOXIDE CARBON (DLCO) AND FORCED VITAL CAPACITY (FVC) IN PREDICTING THE ONSET OF SYSTEMIC SCLEROSIS (SSC)-INTERSTITIAL LUNG DISEASE (ILD) IN THE EUROPEAN SCLERODERMA TRIALS AND RESEARCH (EUSTAR) DATABASE}

G. Lepri ${ }^{1}$, C. Bruni ${ }^{1}$, L. Tofani ${ }^{1}$, A. Moggi Pignone ${ }^{2}$, M. Orlandi ${ }^{1}$, T. Sara ${ }^{3}$, M. Hughes ${ }^{4}$, F. Del Galdo ${ }^{5}$, R. Irace ${ }^{6}$, O. Distler ${ }^{7}$, V. Riccieri ${ }^{8}$, Y. Allanore ${ }^{9}, A$ M. Gheorghiu ${ }^{10}$, E. Siegert ${ }^{11}$, J. De Vries-Bouwstra ${ }^{12}$, E. Hachulla ${ }^{13}$, M. Tikly ${ }^{14}$, N. Damjanov ${ }^{15}$, F. Spertini ${ }^{16}$, L. Mouthon ${ }^{17}$, A. M. Hoffmann-Vold ${ }^{18}$, A. Gabrielli ${ }^{19}$ S. Guiducci ${ }^{1}$, M. Matucci-Cerinic ${ }^{1}$, D. Furst ${ }^{1,20}$, S. Bellando Randone ${ }^{1}$ on behalf of EUSTAR. ${ }^{1} \mathrm{AOU}$ Careggi, University of Florence, Division of Rheumatology, Florence, Italy; ${ }^{2} \mathrm{AOU}$ Careggi, University of Florence, Division of Internal Medicine, Florence, Italy; ${ }^{3} \mathrm{AOU}$ Careggi, University of Florence, Interventional Pulmonology Unit, Florence, Italy; ${ }^{4}$ Royal Hallamshire Hospital, Sheffield Teaching Hospitals NHS Foundation Trust, Department of Rheumatology, Sheffield, United Kingdom; ${ }^{5}$ NIHR Biomedical Research Centre and Leeds Institute of Rheumatic and Musculoskeletal Medicine, University of Leeds, Raynaud's and Scleroderma Programme, Leeds, United Kingdom; ${ }^{6}$ University of Campania "Luigi Vanvitelli", Rheumatology Unit, Department of Precision Medicine, Naples, Italy; ${ }^{7}$ Univ Hospital Zurich, University of Zurich, Department of Rheumatology, Zurich, Switzerland; ${ }^{8}$ Rheumatology Unit, "Sapienza" University, Rome, Italy; ${ }^{9}$ Hopital Cochin, University of Paris, Rheumatology
Department, Paris, France; ${ }^{10}$ Cantacuzino Hospital, Carol Davila University of Medicine and Pharmacy, Internal Medicine \& Rheumatology Department, Bucharest, Romania; ${ }^{11}$ Charite University Hospital, Rheumatology, Berlin, Germany; ${ }^{12}$ Leiden University Medical Center, Department of Rheumatology, Leiden, Netherlands: ${ }^{13}$ Centre Hospitalier Universitaire, Service de Médecine Interne, Lille, France; ${ }^{14}$ Chris Hani Baragwanath Academic Hospital University of the Witwatersrand, Division of Rheumatology, Department of Internal Medicine, Johannesburg, South Africa; ${ }^{15}$ University Belgrade Medical School, Institute of Rheumatology, Belgrade, Serbia; ${ }^{16} \mathrm{CHUV}, 16$. Service Immunologie et Allergie, Lausanne, Switzerland; ${ }^{17}$ National Referral Center for Rare Systemic Autoimmune Diseases, Hôpital Cochin, University Paris Descartes, Paris, France; ${ }^{18}$ Oslo University Hospital, Department of Rheumatology, Oslo, Norway; ${ }^{19}$ Università Politecninca delle Marche, Department of Clinical and Molecular Science, Ancona, Italy; ${ }^{20}$ University Califonia Los Angeles, Division Rheumatology, Los Angeles, United States of America

Background: In SSc, ILD is a major cause of morbidity and mortality. High resolution computed tomography (HRCT) is the gold standard for the diagnosis Predictors of ILD onset are eagerly awaited to improve SSc-ILD management Pulmonary function test (PFTs) are routinely performed to measure lung function changes.

Objectives: Our aim was to investigate the performance of DLCO (diffusing capacity of lung carbon monoxide) and FVC (forced vital capacity) in predicting the development of SSc-ILD.

Methods: The longitudinal data of DLCO, FVC and ILD on HRCT of SSc patients from the EUSTAR database were evaluated at baseline $\left(t_{0}\right)$, after $12( \pm 4)\left(t_{1}\right)$ and $24( \pm 4)\left(t_{2}\right)$ months. Patients with negative HRCT for any sign of ILD both at $t_{0}$ and $t_{1}$ were included. Patients who presented or developed pulmonary hypertension during the study period were excluded. At baseline, demographic data, disease duration from Raynaud's onset, disease subsets, autoantibodies and other laboratory and instrumental data were recorded.

Results: $474 / 17805$ patients were eligible for the study (403 females, 71 males): $26.0 \%$ dcSSc, $58.3 \%$ IcSSc, $220(48.0 \%)$ patients with positive anticentromere antibodies (ACA) and $117(25.4 \%)$ with positive antitopoisomerase I antibodies (Topo-I abs). Among all enrolled patients, 46 (9.7\%) developed HRCT signs of ILD at $t$. Patients with Topo-I abs showed an association with ILD development at $\mathrm{t}_{2}(16.7 \%$ vs $7.8 \%, \mathrm{p}=0.0031)$, contrarily ACA positive patients were negatively associated with ILD appearance after 2 years of follow-up (4.4\% vs $14.4 \%$, $\mathrm{p}=0.0001$ ). Positive $\mathrm{t}_{2}$ HRCT patients had a significant lower value of DLCO and FVC at all three assessments when compared to patients with a negative HRCT at $t_{2}$ (Table 1) and both $t_{0}$ DLCO and FVC values negatively correlated with ILD development (Table 1). The mean $t_{\text {to }} t_{1}$ change $(\Delta)$ of DLCO in patients with negative $t_{2}$ HRTC and positive $t_{2}$ HRCT were $-0.5( \pm 12.6)$ and $-1.0( \pm 15.1)$, respectively. The mean $t_{0}$ to $t_{1} \Delta F V C$ in patients with negative $t_{2} H R T C$ and pos itive $t$ HRCT were $-0.2( \pm 10.6)$ and $0.1( \pm 11.5)$, respectively. None of them predicted the appearance of ILD at $t_{2}$ ( $\triangle D L C O:$ OR (IC) 0.997 (0.97-1.02), $p=0.8024$ $\triangle$ FVC OR (IC) $1.002(0.97-1.03), p=0.8664)$. The data showed an association between $t_{0}$ DLCO value $<80 \%$ and ILD appearance after 2 years of follow-up [OR(IC): 3.09(1.49-6.40), $p=0.0023]$. Such association was not observed for $t$ FVC value $<80 \%$ [OR(IC): $1.95(0.81-4.68), p=0.1329]$. The predictive capability of t $\mathrm{DLCO}<80 \%$ was moderate but stronger than FVC $<80 \%$ [AU ROC: $0.62(0.56$ $0.69), 0.53(0.48-0.59)$ respectively, $\mathrm{p}=0.0205]$.

Conclusion: Our data suggest that an impaired baseline DLCO $(<80 \%)$ may have a predictive value for the development of ILD on HRCT after 2 years of follow-up. Further rigorous prospective studies are warranted to understand the role of DLCO evaluation in the course of SSc.

Table 1. DLCO and FVC values at $t_{0}, t_{1}$ and $t_{2}$ values in patients with positive or negative HRCT for ILD at $t_{2}$ and their statistical differences.

\begin{tabular}{|c|c|c|c|c|}
\hline & $\begin{array}{l}\text { Patients without ILD } \\
\text { t2 (mean } \pm S D)\end{array}$ & $\begin{array}{r}\text { ents with ILD } \\
(\text { mean } \pm \text { SD) }\end{array}$ & OR (95\%CL) & $\mathrm{p}$-value \\
\hline DLCO at $t_{0}$ & $79.0 \pm 16.6$ & $69.9 \pm 17.4$ & $0.97(0.95-0.99)$ & 0.0006 \\
\hline DLCO at $t^{\circ}$ & $78.4 \pm 16.8$ & $68.9 \pm 18.6$ & $0.97(0.95-0.98)$ & 0.0005 \\
\hline DLCO at $t^{1}$ & $78.0 \pm 17.0$ & $65.1 \pm 19.1$ & $0.95(0.93-0.97)$ & $<0.0001$ \\
\hline FVC at $t_{0}$ & $102.2 \pm 17.3$ & $94.6 \pm 16.2$ & $0.97(0.96-0.99)$ & 0.0052 \\
\hline FVC at $t^{0}$ & $101.9 \pm 17.9$ & $94.7 \pm 16.5$ & $0.98(0.96-0.99)$ & 0.0092 \\
\hline FVC at $t_{2}$ & $101.6 \pm 17.6$ & $94.5 \pm 20.0$ & $0.98(0.96-1)$ & 0.0126 \\
\hline
\end{tabular}

Disclosure of Interests: Gemma Lepri: None declared, Cosimo Bruni Speakers bureau: $\mathrm{CB}$ reports personal fees from Actelion, personal fees from Eli Lilly, Grant/ research support from: $C B$ reports personal fees from Actelion, personal fees from Eli Lilly, grants from European Scleroderma Trial and Research (EUSTAR) group, grants from New Horizon Fellowship, grants from Foundation for Research in Rheumatology (FOREUM), grants from Fondazione Italiana per la Ricerca sull'Artrite (FIRA), outside the submitted work, Lorenzo Tofani: None declared, Alberto Moggi Pignone: None declared, Martina Orlandi: None declared, Tomasetti Sara Speakers bureau: Speaker's fees for Roche and Boehringer Ingelheim 
Mike Hughes: None declared, Francesco Del Galdo: None declared, Rosaria Irace: None declared, Oliver Distler Grant/research support from: OD (last three years) has/had consultancy relationship and/or has received research funding in the area of potential treatments for systemic sclerosis and its complications from (last three years): Abbvie, Acceleron Pharma, Amgen, AnaMar, Arxx Therapeutics, Baecon Discovery, Blade Therapeutics, Bayer, Boehringer Ingelheim, ChemomAb, Corbus Pharmaceuticals, CSL Behring, Galapagos NV, Glenmark Pharmaceuticals, GSK, Horizon (Curzion) Pharmaceuticals, Inventiva, iQvia, Italfarmaco, iQone, Kymera Therapeutics, Lilly, Medac, Medscape, Mitsubishi Tanabe Pharma, MSD, Novartis, Pfizer, Roche, Sanofi, Serodapharm, Topadur, Target Bioscience and UCB. Patent issued "mir-29 for the treatment of systemic sclerosis" (US8247389, EP2331143)., Valeria Riccieri: None declared, Yannick Allanore Speakers bureau: YA received personal fees from Boehringer, Sanofi, Menarini and Medsenic and grants from Alpine with regards to the management of systemic sclerosis, Grant/research support from: YA received personal fees from Boehringer, Sanofi, Menarini and Medsenic and grants from Alpine with regards to the management of systemic sclerosis, Ana Maria Gheorghiu: None declared, Elise Siegert: None declared, Jeska de Vries-Bouwstra: None declared, Eric Hachulla: None declared, Mohammed Tikly: None declared, Nemanja Damjanov: None declared, Francois Spertini: None declared, Luc Mouthon: None declared, Anna-Maria Hoffmann-Vold Speakers bureau: AMHV: received consulting fees from Actelion, ARXX, Bayer, Boehringer Ingelheim, Lilly, Medscape, Merck Sharp \& Dohme and Roche; and grants from Boehringer Ingelheim., Consultant of: AMHV: received consulting fees from Actelion, ARXX, Bayer, Boehringer Ingelheim, Lilly, Medscape, Merck Sharp \& Dohme and Roche; and grants from Boehringer Ingelheim., Grant/research support from: AMHV: received consulting fees from Actelion, ARXX, Bayer, Boehringer Ingelheim, Lilly, Medscape, Merck Sharp \& Dohme and Roche; and grants from Boehringer Ingelheim., Armando Gabrielli: None declared, Serena Guiducci: None declared, Marco Matucci-Cerinic Speakers bureau: has received consulting fees or honorarium from Actelion, Janssen, Inventiva, Bayer, Biogen, Boehringer, CSL Behring, Corbus, Galapagos, Mitsubishi, Samsung, Regeneron, Acceleron, MSD, Chemomab, Lilly, Pfizer, Roche, Grant/research support from: has received consulting fees or honorarium from Actelion, Janssen, Inventiva, Bayer, Biogen, Boehringer, CSL Behring, Corbus, Galapagos, Mitsubishi, Samsung, Regeneron, Acceleron, MSD, Chemomab, Lilly, Pfizer, Roche, Daniel Furst: None declared, Silvia Bellando Randone: None declared

DOI: 10.1136/annrheumdis-2021-eular.3027

\section{POS0318 CLINICAL PHENOTYPE IN SCLERODERMA PATIENTS WITH ANTI-TOPOISOMERASE I POSITIVITY AND LIMITED CUTANEOUS FORM: DATA FROM THE EUSTAR DATABASE}

E. Zanatta ${ }^{1}$, D. Huscher ${ }^{2}$, P. Airò ${ }^{3}$, A. Balbir-Gurman ${ }^{4}$, E. Siegert ${ }^{5}$, A. Ortolan ${ }^{1}$ M. Matucci-Cerinic ${ }^{6}$, F. Cozzi ${ }^{7}$, G. Riemekasten ${ }^{8}$, A. M. Hoffmann-Vold ${ }^{9}$, O. Distler ${ }^{10}$, A. Gabrielli $i^{11}$, S. Heitmann ${ }^{12}$, N. Hunzelmann ${ }^{13}$, C. Montecucco ${ }^{14}$ J. Morovic-Vergles ${ }^{15}$, C. Ribi ${ }^{16}$, A. Doria ${ }^{1}$, Y. Allanore ${ }^{17}$ on behalf of on behalf of EUSTAR collaborators. ${ }^{1}$ University Hospital of Padova, Department of Medicine, Rheumatology Unit, Padova, Italy; ${ }^{2}$ Charité-Universitaetsmedizin, Institute of Biometry and Clinical Epidemiology and Berlin Institute of Health, Berlin, Germany; ${ }^{3}$ Spedali Civili, Rheumatology and Clinical Immunology, Brescia, Italy; ${ }^{4}$ Rappaport Faculty of Medicine, B. Shine Rheumatology Institute Rambam Health Care Campus, Technion, Haifa, Israel; ${ }^{5}$ Charité-Universitatsmedizin Berlin, Department of Rheumatology and Clinical Immunology, Berlin, Germany; ${ }^{6}$ University of Florence, Department of Experimental and Clinical Medicine, Division of Rheumatology, Florence, Italy; ${ }^{7}$ Ospedale Classificato Villa Salus, Internal Medicine Unit, Venice, Italy; ${ }^{8}$ Universitatsklinikum Schleswig HolsteinCampus Lubeck, Department of Rheumatology, Lubeck, Germany; ${ }^{9}$ Oslo University Hospital, Department of Rheumatology, Oslo, Norway; ${ }^{10}$ University Hospital Zurich, University of Zurich, Department of Rheumatology, Zurich, Switzerland; ${ }^{11}$ Università Politecnica delle marche, Dipartimento di Scienze Cliniche e molecolari, Ancona, Italy; ${ }^{12}$ Marienhospital Stuttgart Böheimstrasse, Department of Rheumatology, Stuttgart, Germany; ${ }^{13}$ University of Cologne, Department of Dermatology, Koln, Nordrhein-Westfalen, Germany; ${ }^{14}$ IRCCS Policlinico San Matteo Foundation, Department of Rheumatology, Pavia, Italy; ${ }^{15}$ Dubrava University Hospital, Department of Internal Medicine, Division of Clinical Immunology, Allergology and Rheumatology, Zagreb, Croatia;

${ }^{16}$ Lausanne University Hospital and University of Lausanne, Department of Rheumatology, Clinical Immunology and Allergy, Lausanne, Switzerland; ${ }^{17}$ Cochin Hospital, University of Paris Descartes, Department of Rheumatology, Paris, France

Background: There is renewed interest in the role of autoantibodies to predict outcomes in systemic sclerosis (SSc). Among the newly identified subsets, patients with limited cutaneous form (IcSSc) but anti-topoisomerase I antibodies (Scl70) positivity draw particular attention, and namely, assessing the risk of developing interstitial lung disease (ILD) -the main cause of death in SSc-to improve the management of Scl70-IcSSc patients.
Objectives: We aimed to characterize patients with Scl70-IcSSc in the large multicenter European Scleroderma Trial and Research (EUSTAR) cohort.

Methods: The EUSTAR database was locked in July 2019. We included all patients fulfilling 1980 ACR and/or 2013 ACR/EULAR criteria for SSc, with disease duration at database entry $\leq 3$ yrs and known and stable skin form during the first 3 yrs. Patients with IcSSc were compared: Scl70-IcSSc (target group) vs. ACA-IcSSc and ANA-IcSSc (Step 1); and Scl70-IcSSc vs. Scl70-dcSSc (Step 2). In the ANA subgroup we included ANA+ patients with negative SSc-specific antibodies (ScI70, ACA, RNA polymerase III). In each step, we performed 5 generalized mixed models (GMM) for the risk of the new onset of ILD (defined by imaging), primary myocardial involvement (PMI), pulmonary hypertension $(\mathrm{PH})$, "any severe" (ILD+PMI+PH+scleroderma renal crisis) and all-cause-mortality. An additional GMM assessed the risk of forced vital capacity (FVC) decline $\geq 10 \%$ vs. FVC value at ILD onset. Each GMM was adjusted for age, sex and confounders Results: Overall, 1285 SSc patients were included: 1068 (83\%) females, 860 $(67 \%)$ IcSSc and 425 (33\%) dcSSc. Among patients with IcSSc, $537(62 \%)$ had ACA+, $194(23 \%)$ Scl70+ and 129 (15\%) ANAt; 425 patients had dcSSc and Scl70+. Median follow-up was similar in all 4 groups: 7.2 to $8.1 \mathrm{yrs}$.

Step 1: At baseline, Scl70-IcSSc patients had significantly shorter time from Raynaud's phenomenon (RP) to SSc onset, higher mRSS (5.8 \pm 4.8 vs. $4.3 \pm 4$ $\mathrm{p}=0.001$ ), and higher rate of articular and muscular involvement vs. ACA-lcSSc patients (Figure 1). No differences were found between Scl70-IcSSc and ANAIcSSc comparing the aforementioned variables. ILD was more frequent in Scl70-IcSSc (46\%) than in ACA-IcSSc (10\%) and ANA-IcSSc (25\%), as well as restrictive lung disease. GMM showed that Scl70-IcSSc carries a higher risk of ILD than both ACA-IcSSc (HR 4.55, 95\% Cl 3.23-6.67) and ANA-IcSSc (HR 2.17, $95 \% \mathrm{Cl} 1.39-3.45$ ), with a rate of FVC decline $\geq 10 \%$ over time similar to the other limited forms. In Scl70-IcSSc patients the risk of "any severe" organ involvement was similar to ANA-IcSSc and higher than ACA-IcSSc (HR 1.89, 95\% Cl 1.402.50). In particular, Scl70-IcSSc shows a risk of PMI similar to ANA-IcSSc and lower than ACA-IcSSc; no differences regarding PH risk. The mortality risk in patients with Scl70-IcSSc was similar to the other limited forms:

Step 2: At baseline, time from RP to SSc onset was longer in patients with Scl70IcSSc, with less frequent joint synovitis and tendon friction rubs vs. patients with Scl70-dcSSc. Conversely, the frequency of muscular, cardiac and pulmonary involvement was similar. The risk of ILD in Scl70-IcSSc patients was similar to Scl70-dcSSc, with a lower risk of FVC decline $\geq 10 \%$ over time. The risk of "any severe" involvement ( $\mathrm{HR} 0.66,95 \% \mathrm{Cl} 0.49-0.83$ ), $\mathrm{PMI}$ and $\mathrm{PH}$ was lower and the mortality risk tended to be lower ( $\mathrm{HR} 0.57,95 \% \mathrm{Cl} 0.33-1.01, \mathrm{p}=0.053$ ) vs. Scl70-dcSSc.

Conclusion: In our large multicenter EUSTAR cohort one quarter of IcSSc patients were Scl70+. We show a ranking for major organ involvement within IcSSc: Scl70 the most severe, ANA+ intermediate and ACA the milder form. Scl70-dcSSc patients present the most severe phenotype, and Scl70 positivity, more than the cutaneous subset, is strongly predictive of ILD, whereas other variables may influence progression. These results may provide new insight to improve the management of ScI70-IcSSc patients.

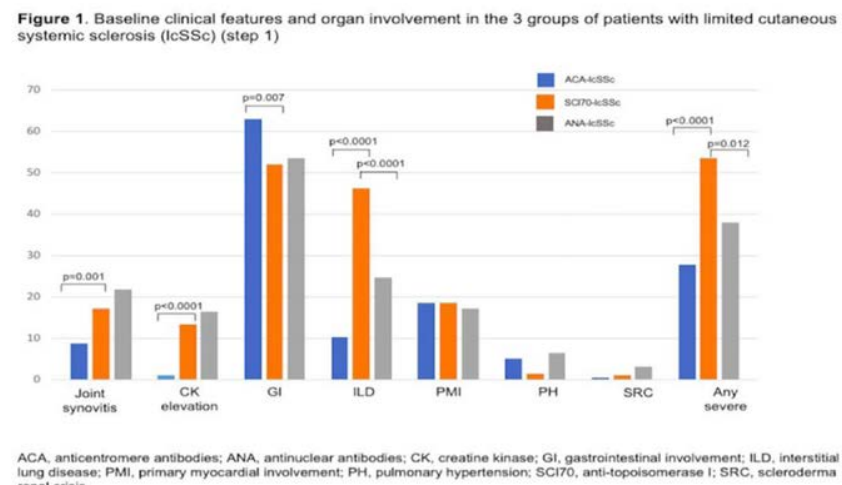

Disclosure of Interests: Elisabetta Zanatta: None declared, Dörte Huscher None declared, Paolo Airò: None declared, Alexandra Balbir-Gurman: None declared, Elise Siegert: None declared, Augusta Ortolan: None declared, Marco Matucci-Cerinic: None declared, Franco Cozzi: None declared, Gabriela Riemekasten: None declared, Anna-Maria Hoffmann-Vold: None declared, Oliver Distler Speakers bureau: has/had consultancy relationship and/or has received research funding in the area of potential treatments for systemic sclerosis and its complications from (last three years): Abbvie, Acceleron Pharma, Amgen, AnaMar, Arxx Therapeutics, Baecon Discovery, Blade Therapeutics, Bayer Boehringer Ingelheim, ChemomAb, Corbus Pharmaceuticals, CSL Behring, Galapagos NV, Glenmark Pharmaceuticals, GSK, Horizon (Curzion) Pharmaceuticals, Inventiva, iQvia, Italfarmaco, iQone, Kymera Therapeutics, Lilly, Medac 